\title{
Isolation of Proteins Related to the Rh Polypeptides from Nonhuman Erythrocytes
}

\author{
Ali M. Saboori, Bradley M. Denker, and Peter Agre \\ Departments of Medicine and Cell Biology/Anatomy, Johns Hopkins University School of Medicine, Baltimore, Maryland 21205
}

\begin{abstract}
It is thought that the $R h$ antigens may be important in maintaining normal erythocyte membrane integrity. Despite their name, $R h$ antigens are serologically present only on human erythrocytes. Rh structural polymorphisms are known to reside within a family of nonglycosylated $M_{\mathbf{r}} 32,000$ integral membrane proteins that can be purified by hydroxylapatite chromatography. $M_{\mathrm{r}} 32,000$ integral membrane proteins were purified similarly from erythrocyte membrane vesicles prepared from rhesus monkeys, cows, cats, and rats, but could not be purified from human $R h_{\text {mod }}$ erythrocytes, a rare syndrome lacking $R h$ antigens. The purified $M_{\mathrm{r}} 32,000$ polypeptides were labeled with ${ }^{125} \mathrm{I}$, digested with chymotrypsin, and found to be $30-60 \%$ identical to human $\mathrm{Rh}$ polypeptides when compared by two-dimensional iodopeptide mapping. The physiologic function of the $\mathrm{Rh}$ polypeptides remains to be identified; however, the existence of related proteins in nonhuman erythrocytes supports the concept that the $\mathbf{R h}$ polypeptides are erythrocyte membrane components of fundamental significance.
\end{abstract}

\section{Introduction}

The complex Rh blood group system is of great clinical importance and has recently been characterized on a molecular level (see reviews 1-3). A family of $M_{\mathrm{r}} 32,000$ erythrocyte integral membrane proteins (referred to as the $R h$ polypeptides) can be surface ${ }^{125}$ I-labeled on intact erythrocytes and immunoprecipitated with antibodies specific for $R h$ (D), (c), and $(E)(4,5)$. No surface carbohydrate has been identified on the $\mathrm{Rh}$ polypeptides (6), and the $\mathrm{Rh}$ polypeptides are associated with the erythrocyte membrane skeleton $(7,8)$. Erythrocytes from $R h(D)$ positive and negative individuals bear $R h$ polypeptides that are similar but nonidentical (9) due to partial divergence among the $\mathrm{D}, \mathrm{c}$, and $\mathrm{E}$ polypeptides $(10,11)$. Purification of the $\mathrm{Rh}$ polypeptides has very recently been achieved by immunological (12) and nonimmunological methods $(9,13)$.

Dr. Saboori's present address is Department of Environmental Health Sciences, Johns Hopkins University School of Hygiene and Public Health. Dr. Denker's present address is Department of Medicine, Brigham and Women's Hospital, Harvard Medical School.

Address correspondence to Dr. Peter Agre, Hunterian 101, Johns Hopkins University School of Medicine, 725 N. Wolfe Street, Baltimore, MD 21205.

Received for publication 6 July 1988 and in revised form 11 August 1988.

J. Clin. Invest.

(C) The American Society for Clinical Investigation, Inc.

0021-9738/89/01/0187/05 \$2.00

Volume 83, January 1989, 187-191
While it has been proposed that the $\mathrm{Rh}$ polypeptides play an essential role in erythrocyte membrane physiology, no primary role has yet been identified. Individuals with the rare $R h_{\text {null }}$ and $R h_{\text {mod }}$ syndromes (14) lack virtually all $D, C, c, E$, and $e$ antigens. $R h_{\text {null }}$ erythrocytes are misshapen and fragile, and suffer from a variety of membrane defects including partial loss of phospholipid bilayer asymmetry (15) and abnormal function of multiple membrane transporters $(16,17)$.

The $\mathrm{Rh}$ antigens are found only on human erythrocytes. The Rh system was mistakenly named after the rhesus monkey due to confusion with the LW antigen (named after Landsteiner and Wiener), but erythrocytes from neither the rhesus monkey, other nonhuman primates, nor any other mammalian species contain the $\mathrm{Rh}$ antigens (18). Chimpanzees have a blood group system with similarities to Rh (19), but the serologically defined surface $\mathrm{Rh}$ epitope has undoubtedly diverged extensively between species, for considerable divergence exists even between $\mathrm{Rh}$ positive and negative humans. Nevertheless, if the core $\mathrm{Rh}$ polypeptides are of general importance to erythrocyte membranes, existence in diverse species should be expected.

Identification of proteins related to the $\mathrm{Rh}$ polypeptides in nonhuman erythrocytes and nonerythroid tissues is not possible with current immunological or molecular genetic methods. $\mathrm{Rh}$-immune globulin reacts strongly with the $\mathrm{Rh}$ antigens only on intact membranes but fails to react on immunoblots. Likewise, no cDNA probe yet exists for identification of mRNA for the $\mathrm{Rh}$ polypeptides. An alternate approach would be to isolate putative nonhuman forms of the Rh polypeptides by the nonimmunological method that exploits the unique behavior of the $\mathrm{Rh}$ polypeptides on hydroxylapatite chromatography. Similarities between isolated proteins and the human $\mathrm{Rh}$ polypeptides may be confirmed by two-dimensional iodopeptide mapping. This report describes successful application of these methods to erythrocytes from four nonhuman species and demonstrates that proteins related to the $\mathrm{Rh}$ polypeptides are general components of mammalian erythrocytes.

\section{Methods}

Human blood anticoagulated with citrate-phosphate-dextrose-adenine solution was obtained from the American Red Cross (Baltimore, MD). Whole human blood from a donor with $\mathrm{Rh}_{\text {mod }}$ phenotype was provided by Dr. Peter Issitt, South Florida Regional Blood Center (Miami, FL). Whole blood was obtained from animal sources by the Johns Hopkins Comparative Medicine Department (Baltimore, MD) and anticoagulated with acid-citrate-dextrose or EDTA. Erythrocyte membrane vesicles were prepared and depleted of all peripheral proteins with $1 \mathrm{M} \mathrm{KI}$, as described by Bennett (20).

Human $\mathrm{Rh}$ polypeptides were purified essentially as described (9). KI-stripped membrane vesicles were prepared from $100-200 \mathrm{ml}$ of human erythrocytes and solubilized in $1.2 \%(\mathrm{wt} / \mathrm{vol}) \mathrm{SDS}, 7.5 \mathrm{mM}$ sodium phosphate (pH 7.4), and 1 mM DTT. A tracer of immunoprecipitated surface ${ }^{125} \mathrm{I}$-labeled $\mathrm{Rh}$ protein was prepared (13) and $\sim 20,000 \mathrm{cpm}$ ( $<1 \mu \mathrm{g}$ protein) was added to the solubilized vesicles. The material was adsorbed onto and eluted from a $1.6 \times 30-\mathrm{cm}$ column packed with high resolution hydroxylapatite (Calbiochem-Beh- 
ring Corp., La Jolla, CA) and eluted isocratically with $0.2 \%$ (wt/vol) SDS, $0.3 \mathrm{M}$ sodium phosphate ( $\mathrm{pH} 7.4$ ), $1 \mathrm{mM} \mathrm{DTT}$, and $1 \mathrm{mM} \mathrm{NaN}_{3}$ followed by a $500-\mathrm{ml}$ gradient of $0.3-0.8 \mathrm{M}$ sodium phosphate in the same buffer. More than $99 \%$ of all protein eluted before the peak of ${ }^{125}$ I-Rh polypeptides, which eluted late in the gradient. The fractions containing the peak of ${ }^{125}$ I-labeled tracer were combined, dialyzed against the same buffer with $7.5 \mathrm{mM}$ sodium phosphate, and concentrated to $20 \mathrm{ml}$. The $\mathrm{Rh}$ polypeptides were further purified by preparative SDS-PAGE. Identical methods were used for isolation of proteins from $50-200 \mathrm{ml}$ of blood from other species.

Two-dimensional iodopeptide maps were prepared from the isolated proteins using a method (9) adapted from that of Elder and colleagues (21). Basically, $10 \mu \mathrm{g}$ of purified protein was precipitated in chilled acetone, solubilized in 5\% SDS, and labeled with $1 \mathrm{mCi}$ of ${ }^{125} \mathrm{I}$ after chloramine $\mathrm{T}$ oxidation. The ${ }^{125} \mathrm{I}$-labeled proteins were isolated by preparative SDS-PAGE, and the desiccated gel slices were digested extensively with alpha chymotrypsin (Cooper Biomedical, Malvern, PA). The released peptides were analyzed in two dimensions on Merck cellulose TLC sheets: $(a)$ electrophoresis, and (b) TLC. Iodopeptides were visualized by autoradiography.

\section{Results}

Isolation of $M_{r} 32,000$ proteins. Hydroxylapatite chromatography of SDS-solubilized membrane vesicles permitted isolation of $M_{\mathrm{r}} 32,000$ erythrocyte integral membrane proteins from each of several nonhuman species. Erythrocytes from the nonhuman species lack serologically detectable $\mathrm{Rh}$ antigens, but hydroxylapatite elutions of the $M_{\mathrm{r}} 32,000$ proteins from each species coincided exactly with the peak of human ${ }^{125} \mathrm{I}-\mathrm{la}-$ beled $\mathrm{Rh}$ polypeptide tracer. Like the Rh polypeptides, the $M_{\mathrm{r}}$ 32,000 proteins eluted only at $0.6-0.8 \mathrm{M}$ sodium phosphate which is above the concentration at which $99 \%$ of all erythrocyte integral membrane proteins are eluted (9).

The $M_{\mathrm{r}} 32,000$ proteins were further purified by preparative SDS-PAGE and were compared with purified human $\mathbf{R h}$ polypeptides (Fig. 1). All of the $M_{\mathrm{r}} 32,000$ proteins migrated with electrophoretic mobilities identical to the human $R h$ polypeptides, and all formed electrophoretic bands with hazy, indistinct margins. Faint bands were also noted in the lanes of the cow and rat preparations (lanes 3 and 5) that corresponded to the human Rh polypeptide dimers. The human and monkey preparations (lanes 1 and 2) were contaminated with a small amount of a protein of $M_{\mathrm{r}} 28,000$ that was determined by immunoblotting (not shown) to be identical to that recently described (23). This contaminant was removed during the SDS-PAGE step of two-dimensional iodopeptide analysis (below). The cow preparation (lane 3) was contaminated by a small amount of a protein of $M_{\mathrm{r}} 31,000$ that may represent degradation of the $M_{\mathrm{r}} 32,000$ protein. Precise determination of the concentrations of the $M_{\mathrm{r}} 32,000$ proteins in nonhuman erythrocytes was not attempted since this would require assumptions based on recovery of the human ${ }^{125}$ I-labeled tracer. Nevertheless, $\sim 100-200 \mu \mathrm{g}$ of protein was isolated from each species, and analysis of SDS-PAGE gels indicated that the overall abundance of the nonhuman $M_{\mathrm{r}} 32,000$ proteins is similar to the abundance of human $\mathrm{Rh}$ polypeptides, $\sim 0.5 \%$ of the total membrane protein $(9,13)$.

Structural similarities. The nonhuman proteins were directly compared with human $R h$ polypeptides to assess the overall degree of similarity between the proteins. The purified proteins were denatured in SDS, labeled to high specific activity with ${ }^{125} \mathrm{I}$, digested with chymotrypsin, and analyzed in two

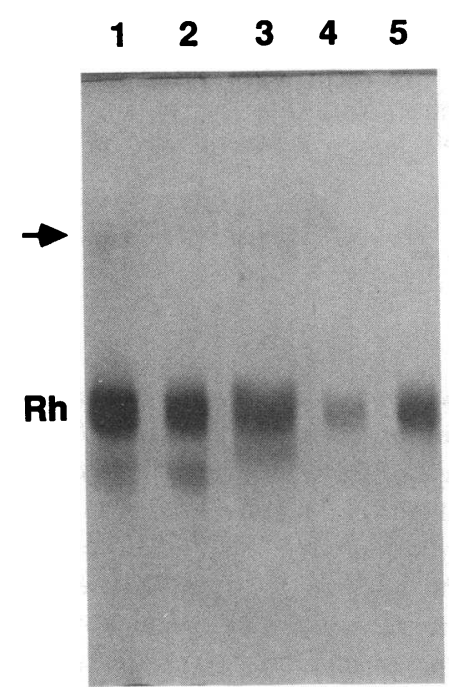

Figure 1. Silver-stained $12 \%$ SDS-PAGE gel (22) of human $\mathrm{Rh}$ polypeptides and $M_{\mathrm{r}}$ 32,000 proteins isolated from erythrocytes of four nonhuman species (see Methods): human (lane 1 ), rhesus monkey (lane 2), cow (lane 3), cat (lane 4), and rat (lane 5). Differences in staining were due to unequal protein loading. The human $\mathrm{Rh}$ polypeptides are labeled " $R h$ " and the dimer is denoted with an arrow. The material of slightly faster electrophoretic mobilities in lanes 1,2 , and 3 is probably contaminant.

dimensions. Such analyses of human $\mathrm{Rh}$ polypeptides have previously demonstrated highly reproducible patterns. The iodopeptides are generally well separated on the two-dimensional maps, although some of the asymmetric spots probably represent partial overlap of two or more different iodopeptides (9). Consistent differences were previously noted between iodopeptides prepared from $\mathrm{Rh}$ polypeptides isolated from $R h(D)-p o s i t i v e$ and -negative humans (9). Two-dimensional iodopeptide maps of human $\mathrm{Rh}$ polypeptides have been shown to represent a composite of $\mathrm{D}, \mathrm{c}$, and $\mathrm{E}$, which are related but nonidentical polypeptides (11).

Two-dimensional iodopeptide maps prepared from the $M_{\mathrm{r}}$ 32,000 proteins isolated from each of the nonhuman species demonstrated a different pattern for each species, but similarities to human $\mathrm{Rh}$ polypeptides were always apparent. Two iodopeptides were consistently identified in the digests of all species (denoted by arrows in Fig. 2, top right). Three iodopeptides were found in the human preparation and three of the four nonhuman preparations. At least three iodopeptides were found only in the human preparation. While the preparations from the different nonhuman species were distinct from one another, several iodopeptides from each nonhuman preparation comigrated with some of the human iodopeptides. Moreover, the shapes of the comigrating iodopeptides were also generally similar. The least homology was noted for the cow preparation from which 5 of 17 iodopeptides directly overlay human iodopeptides. The greatest homology was noted for the rat preparation from which 8 of 14 iodopeptides directly overlay human iodopeptides. Intermediate degrees of homology were noted for the rhesus monkey and cat preparations from which 7 of 18 and 7 of 14 iodopeptides overlay human iodopeptides, respectively. The similarities were highly reproducible when assessed by repeated analyses of the same or newly prepared iodopeptides. Digestions with trypsin were technically less satisfactory due to incomplete digestion and smearing (not shown), yet the overall similarities between human and nonhuman proteins were notable.

\section{Discussion}

This report describes isolation from nonhuman erythrocytes of proteins that are related to the human $\mathrm{Rh}$ polypeptides. The 

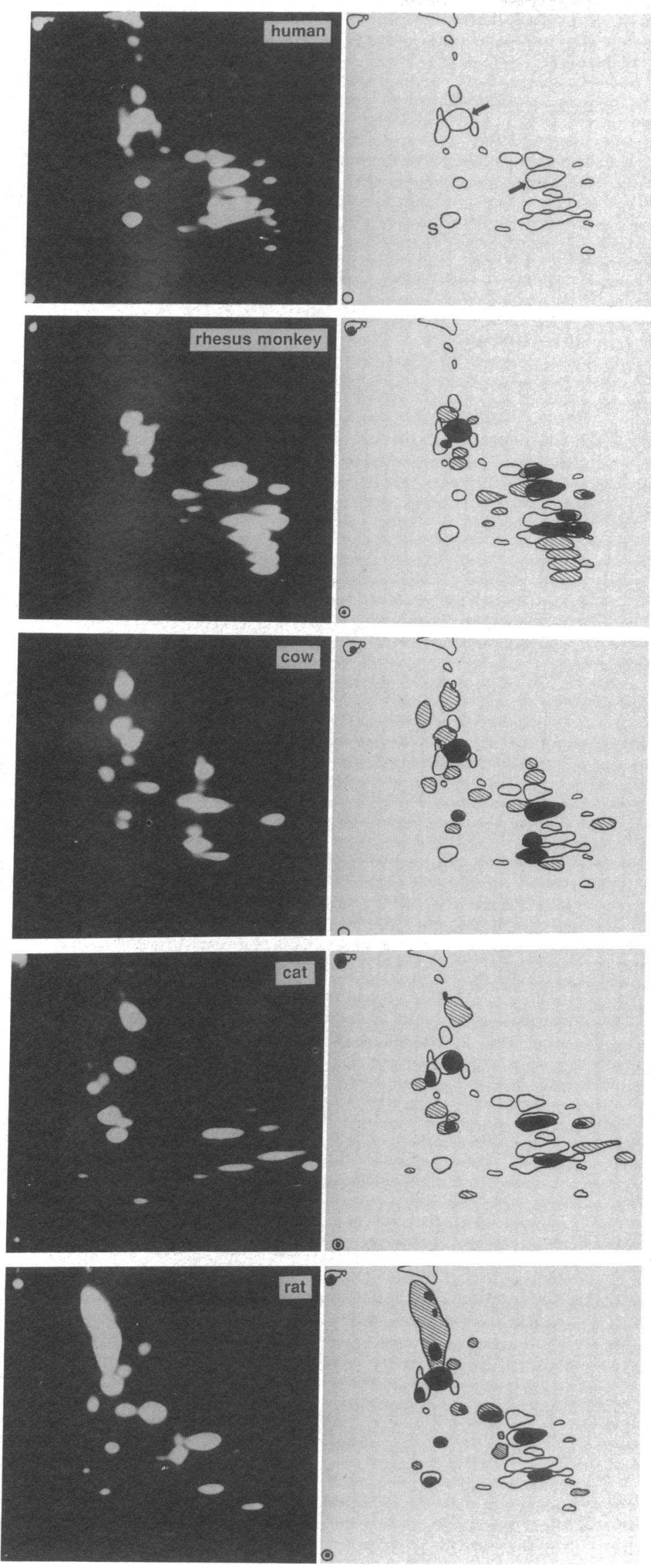

Figure 2. Two-dimensional iodopeptide maps of $M_{\mathrm{r}} 32,000$ $\mathrm{Rh}$ polypeptides isolated from erythrocytes from humans and four nonhuman species. The purified polypeptides were denatured in SDS, labeled with ${ }^{125}$ I, digested with chymotrypsin, and analyzed in two dimensions (see Methods): electrophoresis (horizontal); TLC (vertical); the origin was at the lower left. Autoradiographs of the two-dimensional iodopeptide maps are on the left. Drawing of the autoradiograph of the human preparation is at the upper right; the iodopeptide corresponding to the surface-labeled domain described by Blanchard et al. (11) is denoted "S"; two iodopeptides shared by all species are denoted by arrows.

Composite drawings comparing autoradiographs of nonhuman proteins and the human $\mathrm{Rh}$ polypeptides are on the right: open figures represent iodopeptides specific for human Rh polypeptides; hatched figures represent iodopeptides specific for the indicated species; solid figures represent iodopeptides common to both human and the indicated nonhuman preparation. 
existence of such proteins supports the concept that the core $M_{\mathrm{r}} 32,000 \mathrm{Rh}$ polypeptides are common to all mammalian erythrocytes and implies that they may play a fundamental role in membrane physiology. Identification of such a specific role has not been made, although contribution to the organization of the phospholipid bilayer is a likely possibility (15). Erythrocytes from a human with the $\mathrm{Rh}_{\text {mod }}$ syndrome were the only erythrocytes from which the hydroxylapatite method failed to isolate $M_{\mathrm{r}} 32,000$ polypeptides (data not shown). Presumably the $\mathrm{Rh}_{\text {mod }}$ mutation leads to decreased synthesis or reduced stability of the $M_{\mathrm{r}} 32,000 \mathrm{Rh}$ polypeptides, and this is probably the explanation for the nearly total lack of $\mathrm{Rh}$ antigens and the abnormalities of membrane organization characteristic of this syndrome.

Since the cDNA for the Rh polypeptides has not yet been obtained, isolation and two-dimensional iodopeptide mapping is a useful approach for comparing the $\mathrm{Rh}$ polypeptides to potentially related proteins. This method is limited, since it will only detect peptide fragments containing ${ }^{125} \mathrm{I}$-labeled tyrosines. Also, two-dimensional maps tend to accentuate differences between proteins, and migration of each iodopeptide can be drastically altered by a single amino acid substitution. Identical two-dimensional migration of $30-60 \%$ of iodopeptides from four other species with human iodopeptides is therefore highly significant. Generally $<10 \%$ of iodopeptides derived from unrelated proteins will coincidentally comigrate on two-dimensional maps.

These studies were feasible because of the fortunate, atypical chromatographic behavior of this family of proteins which permitted their isolation by hydroxylapatite chromatography. A nonimmunological approach was essential since $\mathrm{Rh}$ serological activity is not present on the nonhuman erythrocytes. The nonhuman $M_{\mathrm{r}} 32,000$ proteins may not be associated with surface antigens and may not even contain extracellular domains. Unlike the human $\mathrm{D}, \mathrm{c}$, and $\mathrm{E}$ polypeptides which can be ${ }^{125}$ I-labeled on the extracellular surface of intact erythrocytes $(4,5)$, attempts to similarly surface-label the nonhuman erythrocytes failed to consistently label $M_{\mathrm{r}} 32,000$ membrane components (not shown). Indeed, of the iodopeptides from all nonhuman preparations, only the rat preparation contained an iodopeptide that comigrated with the iodopeptide previously demonstrated to correspond to the surface ${ }^{125}$ I-labeled domain of the human Rh polypeptides (Fig. 2, right). Identification of two iodopeptides common to the preparations from all five species indicates that these portions of the protein may be highly conserved. A common functional domain may exist in the $M_{\mathrm{r}} 32,000$ protein which requires a highly specific amino acid sequence for biological activity.

It remains to be established if proteins related to the $R h$ polypeptides exist in nonerythroid tissues. Kidney membranes contain several proteins related to erythrocyte membrane proteins, and membrane proteins of $M_{\mathrm{r}} 24,000,30,000$, and 36,000 were isolated by hydroxylapatite chromatography with elution behavior similar to the $\mathrm{Rh}$ polypeptides. However, when these kidney membrane proteins were analyzed by twodimensional iodopeptide mapping there was no significant similarity to the $\mathrm{Rh}$ polypeptides (data not shown). The complexity of such nucleated cells may preclude this approach which has proven successful for erythrocytes. It is likely that molecular genetic techniques will provide better understanding of the relationships between $\mathrm{Rh}$-related proteins, identifi- cation of their distribution in various tissues, and ultimate elucidation of the normal physiologic function.

\section{Acknowledgments}

The authors thank Ms. Barbara L. Smith for her assistance and Dr. Peter Issitt for sending us $\mathbf{R} \mathbf{h}_{\text {mod }}$ erythrocytes.

This work was supported by National Institutes of Health grant HL-33991 and Basil O'Connor Award 5-490 from the March of Dimes Birth Defects Foundation. Dr. Agre is an Established Investigator of the American Heart Association.

\section{References}

1. Issitt, P. D. 1986. Biochemistry of the Rh blood group system. In Recent Advances in Blood Group Biochemistry. B. Vergelen and W. J. Judd, editors. American Association of Blood Banks, Arlington, VA. 105-138.

2. Cartron, J. P. 1988. Recent advances in the biochemistry of blood group $\mathrm{Rh}$ antigens. In Monoclonal Antibodies against Human Red Blood Cell and Related Antigens. P. Rouger and C. Salmon, editors. Arnette, Paris. 69-97.

3. Gahmberg, C. G. 1988. Molecular characteristics of the blood group Rho(D) molecule. In Subcellular Biochemistry, vol. 12. J. R. Harris, editor. Plenum Press, New York. 95-117.

4. Moore, S., C. F. Woodrow, and D. B. L. McClelland. 1982. Isolation of membrane components associated with human red cell antigens Rho(D), (c), (E) and Fya. Nature (Lond.). 295:529-531.

5. Gahmberg, C. G. 1982. Molecular identification of the human Rho(D) antigen. FEBS (Fed. Eur. Biochem. Soc.) Lett. 140:93-97.

6. Gahmberg, C. G. 1983 . Molecular characterization of the human red cell Rho(D) antigen. EMBO (Eur. Mol. Biol. Organ.) J. 2:223-227.

7. Gahmberg, C. G., and K. K. Karhi. 1984. Association of Rho(D) polypeptides with the membrane skeleton in Rho(D)-positive human red cells. J. Immunol. 133:334-337.

8. Ridgwell, K., M. J. A. Tanner, and D. H. Anstee. 1984. The rhesus (D) polypeptide is linked to the human erythrocyte cytoskeleton. FEBS (Fed. Eur. Biochem. Soc.) Lett. 174:7-10.

9. Saboori, A. M., B. L. Smith, and P. Agre. 1988. Polymorphism in the $M_{\mathrm{r}} 32,000 \mathrm{Rh}$ protein purified from $\mathrm{Rh}(\mathrm{D})$-positive and -negative erythrocytes. Proc. Natl. Acad. Sci. USA. 85:4042-4045.

10. Bloy, C., D. Blanchard, W. Dahr, K. Beyreuther, C. Salmon, and J. P. Cartron. 1988. Determination of the $\mathrm{N}$-terminal sequence of human red cell $R h(D)$ polypeptide and demonstration that the $R h(D)$, (c) and (E) antigens are carried by distinct polypeptide chains. Blood. 72:661-666.

11. Blanchard, D., C. Bloy, P. Hermand, J.-P. Cartron, A. M. Saboori, B. L. Smith, and P. Agre. 1988. Two-dimensional iodopeptide mapping demonstrates erythrocyte $\mathrm{Rh} \mathrm{D}$, c, and $\mathrm{E}$ polypeptides are structurally homologous but nonidentical. Blood. 72:1424-1427.

12. Bloy, C., D. Blanchard, P. Lambin, D. Goossens, P. Rouger, C. Salmon, J.-P. Cartron. 1987. Human monoclonal antibody against $\mathrm{Rh}(\mathrm{D})$ antigen. Partial characterization of the $\mathrm{Rh}(\mathrm{D})$ polypeptide from human erythrocytes. Blood. 69:1491-1497.

13. Agre, P., A. M. Saboori, A. Asimos, and B. L. Smith. 1987. Purification and partial characterization of the $M_{\mathrm{r}} 30,000$ integral membrane protein associated with the erythrocyte $R h(D)$ antigen. $J$. Biol. Chem. 262:17497-17503.

14. Sturgeon, P. 1970. Hematological observations on the anemia associated with blood type $\mathrm{Rh}_{\text {null }}$. Blood. 36:310-320.

15. Kuypers, F., M. Van Linde-Sibenius-Tripp, B. Roelofsen, M. J. A. Tanner, D. J. Anstee, and J. A. F. Op den Kamp. 1984. $\mathbf{R h}_{\text {null }}$ human erythrocytes have an abnormal membrane phospholipid organization. Biochem. J. 221:931-934. 
16. Lauf, P. K., and C. H. Joiner. 1976. Increased potassium transport and ouabain binding in human $\mathrm{Rh}_{\text {null }}$ red blood cells. Blood. 48:457-468.

17. Ballas, S. K., M. R. Clark, N. Mohandas, H. F. Colfer, M. S. Caswell, M. O. Bergren, H. A. Perkins, and S. B. Shohet. 1984. Red cell membrane and cation deficiency in $\mathrm{Rh}_{\text {null }}$ syndrome. Blood. 63:10461055.

18. Masouredis, S. P., M. E. Dupuy, and M. Elliot. 1967. Distribution of the human $R h_{0}(D)$ antigen in the red cells of nonhuman primates. J. Immunol. 98:8-16.

19. Wiener, A. S., J. Moor-Jankowski, E. B. Gordon, and C. H. Kratochvil. 1966. Individual differences in chimpanzee blood, demonstrable with absorbed human anti-RH $\mathrm{R}_{0}$ sera. Proc. Natl. Acad. Sci. USA. 56:458-462.
20. Bennett, V. 1983. Proteins involved in membrane-cytoskeleton association in human erythrocytes: spectrin, ankyrin, and band 3 . Methods Enzymol. 96:313-324.

21. Elder, J. H., R. A. Pickett, J. Hampton, and R. A. Lerner. 1977. Radioiodination of proteins in single polyacrylamide gel slices. J. Biol. Chem. 252:6510-6515.

22. Laemmli, U. K. 1970. Cleavage of structural proteins during the assembly of the head of bacteriophage T4. Nature (Lond.). 227:680-685.

23. Denker, B. M., B. L. Smith, F. P. Kuhajda, and P. Agre. 1988. Identification, purification, and partial characterization of a novel $M_{\mathrm{r}}$ 28,000 integral membrane protein from erythrocytes and renal tubules. J. Biol. Chem. 263:15634-15642. 